\title{
Parthenocarpy in the Tomato (Solanum lycopersicum L.) Cultivar 'MPK-1' is Controlled by a Novel Parthenocarpic Gene
}

\author{
Rihito Takisawa ${ }^{1 *}$, Takayuki Maruyama1, Tetsuya Nakazaki ${ }^{1}$, Keiko Kataoka², \\ Hiroki Saito ${ }^{1}$, Sota Koeda ${ }^{3}$, Tsukasa Nunome ${ }^{4}$, Hiroyuki Fukuoka ${ }^{4 * *}$ and Akira Kitajima ${ }^{1}$
}

${ }^{1}$ Graduate School of Agriculture, Kyoto University, Kizugawa 619-0218, Japan

${ }^{2}$ Faculty of Agriculture, Ehime University, Matsuyama 790-8566, Japan

${ }^{3}$ Faculty of Agriculture, Kinki University, Nara 631-8505, Japan

${ }^{4}$ NARO Institute of Vegetable and Floriculture Science, Tsu 514-2392, Japan

Parthenocarpy is a trait where fruit set and growth are triggered without pollination and fertilization. In the tomato (Solanum lycopersicum L.), this trait is considered attractive as it reduces the cost and labor requirements for fruit setting. In this study, we investigated the inheritance of parthenocarpy in 'MPK-1'-a parthenocarpic tomato cultivar derived from a cross between a variant from a self-fertilization posterity of 'Severianin', which exhibited strong parthenocarpy and a non-parthenocarpic cultivar. It was reported that 'MPK-1' contains a pat-2 gene because 'Severianin' which has a pat-2 gene is its only parthenocarpic ancestor. However, we found that parthenocarpy in 'MPK-1' is controlled by a novel parthenocarpic gene, not pat-2. This novel gene, which was designated as Pat-k, is semi-dominant and located on chromosome 1 . We also showed that the size of the parthenocarpic fruit of 'MPK-1' is similar to that of the pollinated fruit at maturity. Thus, 'MPK-1' may be used as a new parthenocarpic resource for breeding.

Key Words: linkage analysis, parthenocarpic fruit development, pat-2, Pat-k.

\section{Introduction}

Fruit set and growth in the tomato are usually triggered by pollination and fertilization, as is the case for many other plants. Tomato flowers are self-pollinated when shaken by the wind or flower-visiting insects. However, in a greenhouse there is little wind and few flower visiting insects, resulting in unstable fruit set. Therefore, growth regulators such as synthetic auxins or bumblebees (Bombus spp.) are needed to stabilize the fruit set. However, the application of synthetic auxins incurs additional financial and labor costs to farmers, and can induce the development of malformed fruit under high-temperature conditions (Hosoki and Asahira, 1978). In contrast, the use of bumblebees results in the production of high-quality fruit (Velthuis and Van Doorn, 2006), but also incurs a high cost and

Received; July 28, 2016. Accepted; January 10, 2017. First Published Online in J-STAGE on March 3, 2017.

This work was supported by a Grant-in-Aid for Young Scientists (B) [15K18639] from the Japan Society for the Promotion of Science.

* Corresponding author (E-mail: takiawa@kais.kyoto-u.ac.jp).

** Present address: Takii Plant Breeding and Experiment Station, Konan 520-3231, Japan. requires the maintenance of optimum temperatures to keep them active.

Parthenocarpy is a trait where fruit set and growth are triggered without pollination and fertilization. In the tomato, this trait is considered attractive as it reduces the financial and labor costs of fruit setting. There are currently five parthenocarpic tomato resources that are controlled by eight different parthenocarpic genes'Soressi' and 'Montfavet191' (pat), 'Severianin' (pat-2), 'RP75/59' (pat3/pat4), 'IL5-1' (pat4.1/pat5.1), and 'IVT-line1' (pat4.2/pat9.1) (Gorguet et al., 2005, 2008). Genetic linkage maps have been constructed for five of these genes, pat, pat4.1, pat4.2, pat5.1, and pat9.1 (Beraldi et al., 2004; Gorguet et al., 2008), and pat-2 was recently mapped to chromosome 4 and found to encode a zinc finger homeodomain protein (Nunome et al., 2013).

The parthenocarpic cultivar 'Severianin', which has the pat-2 gene, is a parthenocarpic tomato breeding resource used in Japan. Some parthenocarpic cultivars, such as 'Renaissance' (Sugahara et al., 2002), 'Paruto', and 'House Paruto' (SAKATA SEED CORPORATION, Japan) were developed using the pat-2 gene and are commercially available. 'MPK-1' is a Japanese parthe- 
nocarpic tomato cultivar that is commercially cultivated in Kyoto, under the name 'Kyo-temari'. 'MPK-1' exhibits stable parthenocarpy and produces few seeds; therefore, the seedlings are vegetatively propagated from cuttings and lateral buds are taken from parent plants. Hosokawa et al. (2004) reported that 'MPK-1' was derived from a cross between a variant from a selffertilization posterity of 'Severianin', which exhibited strong parthenocarpy and a non-parthenocarpic cultivar. It was reported that 'MPK-1' is a parthenocarpic tomato cultivar with the pat-2 gene because 'Severianin' is its only parthenocarpic ancestor (Takisawa et al., 2012). However, seed formation in 'MPK-1' is severely inhibited and it has a very low seed germination rate (Takisawa et al., 2012), whereas 'Severianin' does not exhibit male or female sterility (Lin et al., 1983) and produces normal seeds through pollination. Thus, there are some differences between these two cultivars in terms of seed formation. Parthenocarpy in the tomato is reported to be strongly related to flower morphology and seed formation (Ampomah-Dwamena et al., 2002; Mazzucato et al., 1998). Therefore, 'MPK-1' may contain parthenocarpic gene(s) other than pat-2.

In this study, we performed genetic analyses to elucidate the parthenocarpic gene in 'MPK-1', and showed that 'MPK-1' has a novel parthenocarpic gene that is not pat-2. We also investigated the morphology of 'MPK-1' flowers and fruit to characterize this parthenocarpic gene.

\section{Materials and Methods}

\section{Plant materials}

For the genetic analyses, we developed a population of $F_{2}$ plants $(n=98)$ derived from a cross between the non-parthenocarpic tomato cultivar 'Micro-Tom' (Tomato Growers Supply Company, USA) and the parthenocarpic cultivar 'MPK-1'. For the progeny test, an $\mathrm{F}_{3}$ line was developed from a single $\mathrm{F}_{2}$ plant that was assumed to be heterozygous for parthenocarpy. Four cultivars were used for genotyping with polymerase chain reaction (PCR)-based markers for the Pat-2 locus: the non-parthenocarpic cultivar 'Micro-Tom', and the parthenocarpic cultivars 'MPK-1', 'Severianin', and 'Renaissance'. 'MPK-1' was also used to examine the development of parthenocarpic and pollinated fruit.

\section{Plant growth conditions}

'MPK-1' cuttings were planted in a 128-cell tray filled with vermiculite and placed in a growth chamber (NK System, Japan) at $25^{\circ} \mathrm{C}$ under a 12 -h photoperiod in July 28, 2013. Seeds of the $F_{2}$ population and 'Micro-Tom' were sown in August 3, 2013, and seeds of the $F_{3}$ population were sown in April 2, 2015. The seeds were sown in a 128-cell tray and placed in a greenhouse. The seedlings were transplanted into containers in a greenhouse in September 3, 2013 and May 3 , 2015, respectively. Plants were grown in a green- house on an Experimental Farm of Kyoto University, Takatsuki $\left(34^{\circ} 51^{\prime} \mathrm{N}, 135^{\circ} 37^{\prime} \mathrm{E}\right)$ in autumn 2013 and spring 2015 , respectively.

Characterization of parthenocarpy and fruit development

To evaluate the parthenocarpic phenotype, we observed the initial development of five flowers that had been emasculated a few days before anthesis. Based on this observation, the $F_{2}$ and $F_{3}$ plants were separated into the following three groups: no parthenocarpy- setting fruit but not growing fruit or dropping flowers; weak parthenocarpy-starting to grow fruit some days after anthesis; and strong parthenocarpy-starting to grow fruit before or at anthesis. All the mature fruits were checked for the absence of seeds.

We also compared the size of the parthenocarpic and pollinated fruit by measuring the diameter of 10 fruits at $0,1,2,3$, and 4 weeks post-anthesis, and at maturity with electronic calipers to evaluate the degree of parthenocarpy in 'MPK-1'.

\section{DNA extraction}

The young leaves were taken from the plants and were reserved in a freezer at $-40^{\circ} \mathrm{C}$. DNA was extracted from frozen leaves using a Nucleon PhytoPure kit (GE Healthcare, UK) according to the manufacturer's instructions with some minor modifications.

PCR-based marker analysis to differentiate Pat-2 alleles

A PCR-based marker was used to distinguish between Pat-2 alleles. The primers of the marker were designed using the sequence of the Pat-2 locus: forward primer sequence (Pat-2_fwd), GGCATTAGGTGGT GGTAATGA; reverse primer sequence (Pat-2_rev), GATGAGTCTGTTGCCCCACT (Nunome et al., 2013). We used a PCR machine (TAKARA BIO INC, Japan) in all PCR experiments. PCR reactions were performed in a total volume of $10 \mu \mathrm{L}$ using BIOTAQ ${ }^{\mathrm{TM}}$ DNA polymerase (Bioline, UK) according to the manufacturer's instructions with some minor modifications. Amplification was carried out under the following conditions: $94^{\circ} \mathrm{C}$ for $5 \mathrm{~min} ; 30$ cycles of $94^{\circ} \mathrm{C}$ for $30 \mathrm{~s}$, $58^{\circ} \mathrm{C}$ for $45 \mathrm{~s}$, and $72^{\circ} \mathrm{C}$ for $30 \mathrm{~s}$; and a final extension step at $72^{\circ} \mathrm{C}$ for $7 \mathrm{~min}$. The PCR products were run on $1.0 \%$ agarose gels and stained with ethidium bromide.

Genomic sequence analysis of the Pat-2 locus in 'MPK-1'

The Pat-2 gene has been reported to correspond to a putative gene Solyc04g080490 in the International Tomato Annotation Group (ITAG) release 2.40. We determined the genome sequence of 'MPK-1' spanning 2550 nucleotides, corresponding to 64653386 to 64650837 of SL2.50ch04, which would include the entire sequence of the Solyc04g080490 gene. Four overlapping genome DNA fragments were amplified using four sets of primers (F1: AGAGGCGAGGTCGAGTC 
TAG and R1: ACCATCCGTAACATTTCCACCA; F2: GGCATTAGGTGGTGGTAA and R2: GATGAGTCTG TTGCCCCACT; F3: TACCTAACAACGTTGGCGCT and R3: TCTTGACTCCAACTTGTGAGCA; F4: GT GGGGCAACAGACTCATCA and R4: TAAAGCGG CATCATGAGTGG). PCR reactions were performed in a total volume of $50 \mu \mathrm{L}$ using $\mathrm{BIOTAQ}^{\mathrm{TM}}$ DNA polymerase (Bioline) according to the manufacturer's instructions. Amplification was carried out under the following conditions: $94^{\circ} \mathrm{C}$ for $5 \mathrm{~min} ; 35$ cycles of $94^{\circ} \mathrm{C}$ for $30 \mathrm{~s}, 58^{\circ} \mathrm{C}$ for $1 \mathrm{~min}$, and $72^{\circ} \mathrm{C}$ for $2 \mathrm{~min}$; and a final extension step at $72^{\circ} \mathrm{C}$ for $7 \mathrm{~min}$. The PCR products were run on $1.0 \%$ agarose gels and stained with ethidium bromide to confirm their amplification, after which they were purified with an EZ-10 Spin Column DNA Gel Extraction Kit (BioBasic Inc, Canada). Sequencing was performed by the FASMAC sequencing service (Fasmac, Japan).

\section{Simple sequence repeat (SSR) marker analysis}

Primer data for the SSR markers reported by Shirasawa et al. (2010) and Ohyama et al. (2009) were obtained from the Tomato Marker Database (http:// marker.kazusa.or.jp/Tomato/) and VegMarks (http:// vegmarks.nivot.affrc.go.jp/), respectively. In total, we used 670 SSR markers from the Tomato Marker Database and 212 SSR markers from VegMarks to detect polymorphisms between 'Micro-Tom' and 'MPK-1'. For the SSR markers from the Tomato Marker Database, the PCR reactions were performed in a total volume of $8 \mu \mathrm{L}$ using BIOTAQ $^{\mathrm{TM}}$ DNA polymerase (Bioline) according to the manufacturer's instructions with some minor modifications. Amplification was carried out under the following conditions: $94^{\circ} \mathrm{C}$ for $5 \mathrm{~min} ; 35$ cycles of $94^{\circ} \mathrm{C}$ for $30 \mathrm{~s}$, $58^{\circ} \mathrm{C}$ for $1 \mathrm{~min}$, and $72^{\circ} \mathrm{C}$ for $2 \mathrm{~min}$; and a final extension step at $72^{\circ} \mathrm{C}$ for $7 \mathrm{~min}$. The PCR products were run on $12 \%$ polyacrylamide gels and stained with ethidium bromide. For the SSR markers from VegMarks, the PCR reactions were performed in a total volume of $6 \mu \mathrm{L}$ with a KAPA2G Fast Multiplex PCR Kit (Nippon Genetics, Japan) according to the manufacturer's instructions. Amplification was carried out under the following conditions: $94^{\circ} \mathrm{C}$ for $3 \mathrm{~min} ; 30$ cycles of $94^{\circ} \mathrm{C}$ for $20 \mathrm{~s}, 60^{\circ} \mathrm{C}$ for $30 \mathrm{~s}$, and $72^{\circ} \mathrm{C}$ for $1 \mathrm{~min}$; and a final extension step at $72^{\circ} \mathrm{C}$ for $10 \mathrm{~min}$. Fragments were then amplified with fluorochrome-labeled primers (FAM, VIC, NED, and PET), diluted 200 times with water dissolved in formamide, and analyzed on an automated DNA sequencer (3730 DNA Analyzer; Applied Biosystems, USA) with a GeneScan ${ }^{\mathrm{TM}}-500$ LIZ $^{\circledR}$ Size Standard (Applied Biosystems). Fragment length was determined using GeneMapper ${ }^{\circledR}$ software (Applied Biosystems).

\section{Linkage analysis}

Chi-square tests were performed to examine the goodness of fit between the observed data and the expected Mendelian ratio for $\mathrm{F}_{2}$ populations. Linkage analysis was performed using MAPMAKER ver. 3.0, with a minimum logarithm of odds likelihood score of 3.0 for an $F_{2}$ population (Lander, 1987). The linkage distance between the markers was calculated using the Kosambi mapping function (Kosambi, 1943), while linkage between the parthenocarpic phenotype and the SSR marker in the $\mathrm{F}_{3}$ population was tested using chisquare tests.

\section{Results}

\section{Analysis of the Pat-2 locus in 'MPK-1'}

The sequence of the pat-2 allele of 'Severianin' was determined using the tomato line 'LS935', which is a genetic resource that was obtained by backcrossing 'Severianin' with 'Moneymaker' (Nunome et al., 2013). The open reading frame (ORF) region of the Pat-2 locus in 'Heinz 1706' is $1651 \mathrm{bp}$ in length (https://solgenomics.net/), whereas that of the pat-2 allele of 'LS935' is $617 \mathrm{bp}$ in length. This difference is due to the deletion of a 1034-bp fragment, which was detected by the Pat-2_fwd and Pat-2_rev primers. This primer set amplifies a 1351-bp fragment in the Pat-2 allele and a 317-bp fragment in the pat-2 allele. The amplified fragments of 'Severianin' and 'Renaissance' were detected at the same position as the pat-2 fragment, whereas those of 'Micro-Tom' and 'MPK-1' were detected at the same position as the Pat-2 fragment (Fig. 1). These results indicate that parthenocarpy in 'MPK-1' is not caused by the pat-2 allele of 'Severianin'. To investigate the existence of a small polymorphism, we determined the ORF sequence of the Pat-2 locus in 'MPK-1' using the four sets of primers. This showed that the sequence in 'MPK-1' was identical to that in 'Heinz 1706'.

Segregation data for parthenocarpy in the $F_{2}$ population

We conducted a segregation analysis for parthenocarpy in 'MPK-1' using the $\mathrm{F}_{2}$ population. The $\mathrm{F}_{2}$ population was clearly classified into three groups-no parthenocarpy, weak parthenocarpy, and strong parthenocarpy-according to the time at which the initial growth of unpollinated fruit occurred. Plants that ex-

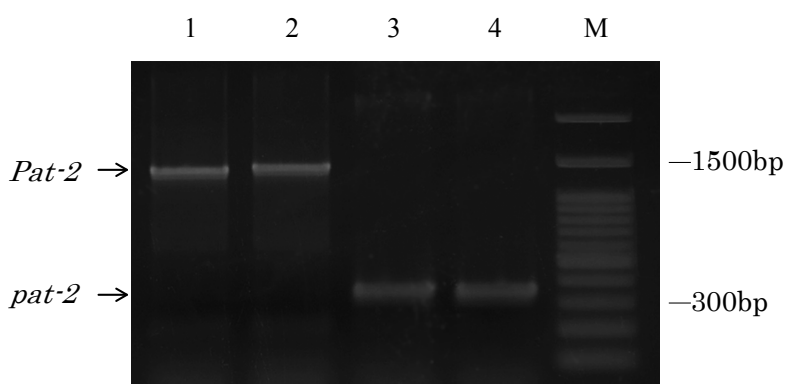

Fig. 1. Polymerase chain reaction-based pat-2 genotyping. Lane: 1, 'Micro-Tom'; 2, 'MPK-1'; 3, 'Renaissance'; 4, 'Severianin'; M, 100-bp ladder. 
Table 1. Polymorphisms of simple sequence repeat (SSR) markers between 'Micro-Tom' and 'MPK-1'.

\begin{tabular}{|c|c|c|c|c|c|c|c|c|c|c|c|c|c|}
\hline \multirow{3}{*}{ Marker type } & \multicolumn{13}{|c|}{ Number of SSR markers } \\
\hline & \multicolumn{12}{|c|}{ Chromosome } & \multirow{2}{*}{ Total } \\
\hline & 1 & 2 & 3 & 4 & 5 & 6 & 7 & 8 & 9 & 10 & 11 & 12 & \\
\hline Polymorphic marker & 9 & 9 & 9 & 9 & 2 & 3 & 2 & 3 & 0 & 3 & 6 & 8 & 63 \\
\hline Non-polymorphic marker & 105 & 50 & 34 & 76 & 55 & 57 & 100 & 74 & 92 & 88 & 40 & 48 & 819 \\
\hline Total & 114 & 59 & 43 & 85 & 57 & 60 & 102 & 77 & 92 & 91 & 46 & 56 & 882 \\
\hline
\end{tabular}

Table 2. Linkage analysis of parthenocarpy with TGS0486, using the $\mathrm{F}_{3}$ line derived from an $\mathrm{F}_{2}$ plant with weak parthenocarpy that was heterozygous for the TGS0486 locus.

\begin{tabular}{|c|c|c|c|c|c|}
\hline \multirow{3}{*}{ Genotype of TGS0486 } & \multicolumn{4}{|c|}{ Number of plants } & \multirow{3}{*}{$\begin{array}{c}\text { Test of } \\
\text { independence }\end{array}$} \\
\hline & \multirow{2}{*}{ Total } & \multicolumn{2}{|c|}{ Parthenocarpy } & \multirow{2}{*}{$\begin{array}{c}\text { No } \\
\text { parthenocarpy }\end{array}$} & \\
\hline & & Strong & Weak & & \\
\hline Micro-Tom homozygous & 14 & 0 & 13 & 1 & \multirow{3}{*}{$\begin{array}{l}\chi^{2}=41.7 \\
P<0.01\end{array}$} \\
\hline Heterozygous & 26 & 1 & 23 & 2 & \\
\hline MPK-1 homozygous & 8 & 8 & 0 & 0 & \\
\hline
\end{tabular}

hibited no parthenocarpy, weak parthenocarpy, and strong parthenocarpy had a segregation ratio of 27:47:24, which was not significantly different from the expected 1:2:1 ratio $\left(\chi^{2}=0.35, P=0.84\right)$. This suggests that each of the three groups of parthenocarpic phenotypes may correspond to different allelic combinations on a single parthenocarpic locus.

\section{Linkage analysis}

We used 882 SSR markers to detect polymorphisms between 'Micro-Tom' and 'MPK-1', 63 of which revealed a polymorphism. These markers were distributed across all chromosomes except chromosome 9 (Table 1). A linkage map constructed from these 63 SSR markers covered $1461 \mathrm{cM}$, with an average linkage distance of $23 \mathrm{cM}$ between markers. To determine the map location of the parthenocarpic locus in 'MPK-1', a linkage analysis was conducted using the genotype data for the 63 SSR markers and the parthenocarpic segregation data with MAPMAKER ver. 3.0. This showed that the parthenocarpic locus was linked to TGS0486, which is located on chromosome 1 . The map distance between TGS0486 and the novel parthenocarpic locus was $28.22 \mathrm{cM}$.

We developed an $\mathrm{F}_{3}$ population from an $\mathrm{F}_{2}$ plant with weak parthenocarpy that was heterozygous for the TGS0486 locus to confirm that the parthenocarpic locus was linked to TGS0486. This resulted in 26 plants that were heterozygous, and 14 and 8 plants that were homozygous for the 'Micro-Tom' allele and the 'MPK-1' allele of the TGS0486 locus, respectively (Table 2). Among the heterozygous plants, 1 plant exhibited strong parthenocarpy, 23 plants exhibited weak parthenocarpy, and 2 plants exhibited no parthenocarpy. Among the plants that were homozygous for the 'Micro-Tom' allele, 13 plants exhibited weak parthenocarpy and 1 exhibited no parthenocarpy, whereas all

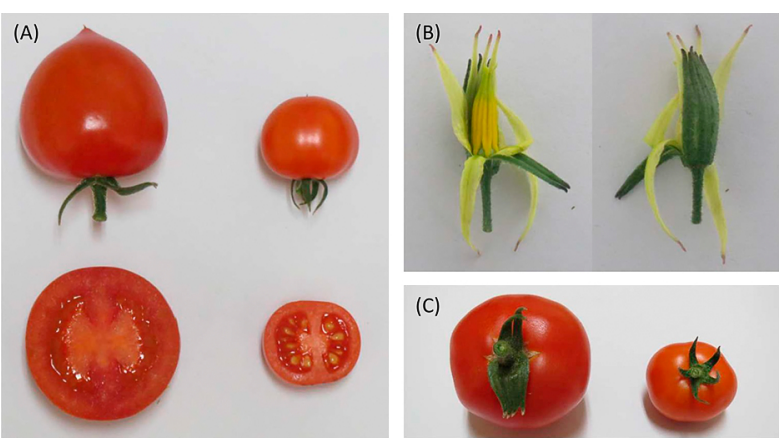

Fig. 2. The flowers and fruit of 'MPK-1' and 'Micro-Tom'. (A) Pollinated fruit of 'MPK-1' (left) and 'Micro-Tom' (right), (B) Flower of 'MPK-1' with fused sepals. The front side of the flower (left) and the back side of the flower (right) (B), (C) Fruit of 'MPK-1' with fused sepals (left) and 'Micro-Tom' with separated sepals (right).

plants that were homozygous for the 'MPK-1' allele exhibited strong parthenocarpy. The linkage analysis for this $\mathrm{F}_{3}$ population showed that the parthenocarpic gene was linked to TGS0486.

\section{Fruit and flower morphology, and fruit development}

The fruit of 'MPK-1' contain few seeds, even when the flowers are sufficiently pollinated (Fig. 2A). In most 'MPK-1' flowers (Fig. 2B), the sepals are fused making it difficult for the petals to open completely at anthesis, and the fused sepals are still observed at the time of harvest (Fig. 2C). The mean diameter of the parthenocarpic fruit was slightly shorter than that of the pollinated fruit between 1 and 3 weeks post-anthesis; however, the fruit were similar in size at 4 weeks post-anthesis and at maturity (Fig. 3).

\section{Discussion}

In this study, we investigated the gene that controls 


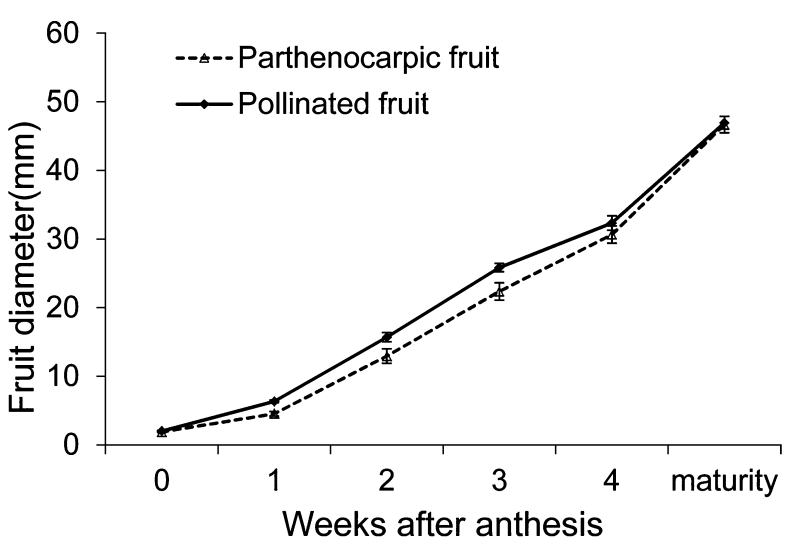

Fig. 3. The development of pollinated fruit and parthenocarpic fruit in 'MPK-1'. Values are means of $8-10$ fruit \pm SE.

parthenocarpy in the tomato cultivar 'MPK-1'. Initially, we analyzed the Pat-2 locus using a PCR-based marker with the cultivars 'MPK-1', 'Severianin', 'Renaissance', and 'Micro-Tom'. We found that the amplified fragments of 'Severianin' and 'Renaissance' were detected at the same position as the pat-2 fragment, whereas the amplified fragment of 'MPK-1' was detected at the same position as the Pat-2 fragment (Fig. 1). In addition, we found that the ORF sequence of Pat-2 locus in 'MPK-1' was identical to that of 'Heinz 1706'. These results suggest that parthenocarpy in 'MPK-1' is not controlled by the pat-2 allele but by some other unknown parthenocarpic gene (Table 2).

The segregation ratio of plants exhibiting no parthenocarpy, weak parthenocarpy, and strong parthenocarpy in the $F_{2}$ population fitted a 1:2:1 ratio, indicating that the parthenocarpic gene of 'MPK-1' is semi-dominant. A linkage analysis of the $F_{2}$ population showed that the parthenocarpic gene is located on chromosome 1, at a distance of $28.22 \mathrm{cM}$ from the nearest SSR marker, TGS0486. A linkage analysis of the $\mathrm{F}_{3}$ population confirmed that TGS0486 is linked to the parthenocarpic gene. However, the segregation ratio of plants exhibiting no parthenocarpy, weak parthenocarpy, and strong parthenocarpy in the $F_{3}$ population did not fit a 1:2:1 ratio because 13 of the $14 \mathrm{~F}_{3}$ plants that were homozygous for the 'Micro-Tom' allele exhibited weak parthenocarpy, with only one having no parthenocarpy. The $\mathrm{F}_{2}$ plants were grown from September to November, whereas the $\mathrm{F}_{3}$ plants were grown from May to July, resulting in the growth temperature of the $\mathrm{F}_{3}$ plants being higher than that of the $F_{2}$ plants. Parthenocarpy is enhanced by high temperatures in the tomato (Sato et al., 2001); therefore, it is possible that the high temperature caused weak parthenocarpy in the $\mathrm{F}_{3}$ plants that were homozygous for the 'Micro-Tom' allele. On the other hand, it is reported that the expression of parthenocarpy in 'Severianin' is affected by not only pat-2, but also some other factors. Lin et al. (1984) reported that the expression of parthenocarpy in 'Severianin' is associ- ated with a determinate growth habit and/or earliness, and Vardy et al. (1989) reported that the minor gene, $m p$, influences the expression of pat-2 in 'Severianin'. Thus, the parthenocarpy of 'MPK-1' may also be affected by minor factors, leading to weak parthenocarpy in the $\mathrm{F}_{3}$ plants that were homozygous for the 'MicroTom' allele. However, all $\mathrm{F}_{3}$ plants that were homozygous for the 'MPK-1' allele exhibited strong parthenocarpy, indicating that the major gene that causes parthenocarpy in 'MPK-1' is located near TGS0486.

It has previously been reported that pat is localized on the long arm of chromosome 3 ; pat-2, pat4.1, and pat4. 2 are localized on chromosome 4; pat5.1 is localized on chromosome 5; and pat9.1 is localized on chromosome 9 (Beraldi et al., 2004; Gorguet et al., 2008; Nunome et al., 2013). Therefore, this is the first report of a parthenocarpic gene on chromosome 1 in the tomato. It has also been reported that the flowers of 'RP75/59', which contain pat3/pat4, need to be emasculated to obtain seedless fruit (Gorguet et al., 2005). However, in 'MPK-1', seed formation was extremely inhibited even when the flowers were sufficiently pollinated. Therefore, it is assumed that the parthenocarpic gene of 'MPK-1' is different from pat-3/pat-4. Vardy et al. (1989) previously hypothesized that two recessive genes, pat-2 and $m p$, are involved in the expression of parthenocarpy in 'Severianin', and that $m p$ influences the expression of pat-2 when it is in the homozygous form. However, the parthenocarpic gene of 'MPK-1' induced strong parthenocarpy by itself, so it is assumed that the parthenocarpic gene of 'MPK-1' is different from $m p$. Based on these findings, it can be concluded that the parthenocarpic gene of 'MPK-1' is a novel parthenocarpic gene. Consequently, we designated this novel parthenocarpic gene Pat-k. Lin et al. (1984) reported that the expression of parthenocarpy among nine lines of 'Severianin' varied significantly in winter cultivation. This may show that there are several parthenocarpic lines in 'Severianin'. There are two possibilities in terms of the origin of Pat-k. First, 'Severianin', which was used as the parent of 'MPK-1', had pat-2 and Pat $k$, and we identified one of them. Second, the parthenocarpic line having not pat-2, but Pat-k, among several parthenocarpic lines of 'Severianin' was used as the parent of 'MPK-1'. 'Severianin', which was used as the parent of 'MPK-1', has been lost. Therefore, we currently cannot clarify where Pat- $k$ is from. Isolation of Pat-k may lead to clarification of where this gene is derived from.

In pat tomato mutants, there are partial aberrations of the stamens and ovules, and fertilization is strongly inhibited even where the ovules appear normal due to abnormalities in the pollen tube-ovary interaction (Mazzucato et al., 1998, 2003), indicating that pat may result from the mutation of a putative gene with homeotic functions. SEPATALA (SEP) is a MADS box gene 
that interacts with other MADS box genes to control the development of each floral whorl in Arabidopsis. Ampomah-Dwamena et al. (2002) showed that constitutive downregulation of a $S E P$ homolog from a tomato, Tomato MADS-box 29 (TM29), results in homeotic conversion and pistil infertility, coupled with parthenocarpic fruit formation. It has previously been reported that pat-2 is a zinc finger homeodomain protein (ZF-HD) gene (Nunome et al., 2013), and Tan and Irish (2006) proposed that this gene family encodes a group of transcriptional regulators with unique biochemical activities that play overlapping regulatory roles in Arabidopsis floral development. In the present study, we found that the sepals of 'MPK-1' were fused, making it difficult for the petals to open completely at anthesis, and the fused sepals were still observed when the fruit were harvested. Fused sepals and the inhibition of seed formation were also observed in the breeding lines derived from 'MPK-1' and the $\mathrm{F}_{3}$ population, which exhibited strong parthenocarpy. In addition, it has previously been reported that seed formation in 'MPK-1' is extremely inhibited and that many ovules have abnormal micropyles (Kataoka et al., 2004; Takisawa et al., 2012). Thus, Pat-k appears to have some homeotic function and the inhibition of seed formation may be caused by genetic pleiotropy of Pat $k$.

In the parthenocarpic cultivar 'Renaissance', which has the pat-2 gene, the parthenocarpic fruit weighs as much as pollinated fruit at maturity (Ohkawa et al., 2007). We also found that the parthenocarpic fruit of 'MPK-1' were similar in size to the pollinated fruit at maturity, which indicates that the Pat-k gene exhibits practical parthenocarpy. Thus, 'MPK-1' may be used as a new parthenocarpic resource for breeding.

In this study, we identified the novel parthenocarpic gene Pat-k in the tomato cultivar 'MPK-1', which may be valuable for the breeding of parthenocarpic tomato varieties. Furthermore, the isolation of Pat- $k$ will increase our understanding of the parthenocarpic mechanism.

\section{Literature Cited}

Ampomah-Dwamena, C., B. A. Morris, P. Sutherland, B. Veit and J. L. Yao. 2002. Down-regulation of TM29, a tomato SEPALLATA homolog, causes parthenocarpic fruit development and floral reversion. Plant Physiol. 130: 605-617.

Beraldi, D., M. E. Picarella, G. P. Soressi and A. Mazzucato. 2004. Fine mapping of the parthenocarpic fruit (pat) mutation in tomato. Theor. Appl. Genet. 108: 209-216.

Gorguet, B., P. M. Eggink, J. Ocana, A. Tiwari, D. Schipper, R. Finkers, R. G. Visser and A. W. van Heusden. 2008. Mapping and characterization of novel parthenocarpy QTLs in tomato. Theor. Appl. Genet. 116: 755-767.

Gorguet, B., A. W. van Heusden and P. Lindhout. 2005. Parthenocarpic fruit development in tomato. Plant Biol. 7: 131-139.

Hosokawa, M., S. Matsumura, T. Hayashi and S. Yazawa. 2004. Plant regeneration of stable parthenocarpic tomato cultivars from shoot apical meristems attached to root tips. Jpn. J. Taste Smell Res. 11: 61-68.
Hosoki, T. and T. Asahira. 1978. In vitro studies of controlling tomato puffiness enhanced by temperature, nitrogen source and sucrose concentration. Sci. Hortic. 9: 295-302.

Kataoka, K., H. Okita, A. Uemachi and S. Yazawa. 2004. A pseudoembryo highly stainable with toluidine blue $\mathrm{O}$ may induce fruit growth of parthenocarpic tomato. Acta Hortic. 637: 213-221.

Kosambi, D. 1943. The estimation of map distances from recombination values. Ann. Eugen. 12: 172-175.

Lander, E. S. 1987. MAPMAKER: An interactive computer package for constructing primary genetic linkage maps of experimental and natural populations. Genomics 1: 174-181.

Lin, S., W. Splittstoesser and W. George. 1983. Factors controlling the expression of parthenocarpy in 'Severianin' tomato. Sci. Hortic. 19: 45-53.

Lin, S., W. Splittstoesser and W. George. 1984. Expression and inheritance of parthenocarpy in 'Severianin' tomato. J. Hered. 75: 62-66.

Mazzucato, A., I. Olimpieri, F. Ciampolini, M. Cresti and G. P. Soressi. 2003. A defective pollen-pistil interaction contributes to hamper seed set in the parthenocarpic fruit tomato mutant. Sex Plant Reprod. 16: 157-164.

Mazzucato, A., A. R. Taddei and G. P. Soressi. 1998. The parthenocarpic fruit (pat) mutant of tomato (Lycopersicon esculentum Mill.) sets seedless fruits and has aberrant anther and ovule development. Development 125: 107-114.

Nunome, T., I. Honda, A. Ohyama, H. Fukuoka, H. Yamaguchi and K. Miyatake. 2013. Parthenocarpy regulation gene and use thereof. Patent WO 2014021398 A1.

Ohkawa, H., S. Sugahara, T. Oyabu, M. Takaichi and K. Yabe. 2007. Effects of high and low temperature conditions on the fruit setting and growth of the parthenocarpic tomato 'Renaissance'. Hort. Res. (Japan) 6: 449-454 (In Japanese with English abstract).

Ohyama, A., E. Asamizu, S. Negoro, K. Miyatake and H. Yamaguchi. 2009. Characterization of tomato SSR markers developed using BAC-end and cDNA sequences from genome databases. Mol. Breed. 23: 685-691.

Sato, S., M. Peet and R. Gardner. 2001. Formation of parthenocarpic fruit, undeveloped flowers and aborted flowers in tomato under moderately elevated temperatures. Sci. Hortic. 90: 243-254.

Shirasawa, K., E. Asamizu, H. Fukuoka, A. Ohyama, S. Sato, Y. Nakamura, S. Tabata, S. Sasamoto, T. Wada, Y. Kishida, H. Tsuruoka, T. Fujishiro, M. Yamada and S. Isobe. 2010. An interspecific linkage map of SSR and intronic polymorphism markers in tomato. Theor. Appl. Genet. 121: 731-739.

Sugahara, S., S. Enomoto, T. Oyabu, Y. Yabe and H. Noguchi. 2002. Breeding of parthenocarpic tomato cultivar 'Renascence'. Res. Bull. Aichi. Agric. Res. CTR. 34: 37-42.

Takisawa, R., K. Kataoka and A. Kitajima. 2012. Inhibition of seed formation by anomalous ovule in 'Kyo-temari', a parthenocarpic tomato (Solanum lycopersicum L.) cultivar. J. Japan. Soc. Hort. Sci. 81: 251-256.

Tan, Q. K. and V. F. Irish. 2006. The Arabidopsis zinc fingerhomeodomain genes encode proteins with unique biochemical properties that are coordinately expressed during floral development. Plant Physiol. 140: 1095-1108.

Vardy, E., D. Lapushner, A. Genizi and J. Hewitt. 1989. Genetics of parthenocarpy in tomato under a low temperature regime: II. Cultivar 'Severianin'. Euphytica 41: 9-15.

Velthuis, H. H. W. and A. Van Doorn. 2006. A century of advances in bumblebee domestication and the economic and environmental aspects of its commercialization for pollination. Apidologie 37: 421-451 